\title{
Ionic Processes in the Gas Phase
}




\section{NATO ASI Series}

\section{Advanced Science Institutes Series}

A series presenting the results of activities sponsored by the NATO Science Committee, which aims at the dissemination of advanced scientific and technological knowledge, with a view to strengthening links between scientific communities.

The series is published by an international board of publishers in conjunction with the NATO Scientific Affairs Division
A Life Sciences
Plenum Publishing Corporation
B Physics
London and New York
C Mathematical and Physical Sciences
D. Reidel Publishing Company
Dordrecht, Boston and Lancaster
D Behavioural and Social Sciences
Martinus Nijhoff Publishers
E Engineering and
The Hague, Boston and Lancaster
Materials Sciences
F Computer and Systems Sciences
G Ecological Sciences
Springer-Verlag
Berlin, Heidelberg, New York and Tokyo

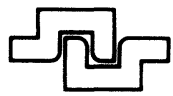

Series C: Mathematical and Physical Sciences Vol. 118 


\section{Ionic Processes in the Gas Phase}

edited by

\section{A. Almoster Ferreira}

Faculty of Sciences, University of Lisbon, Portugal

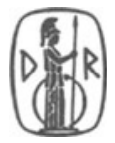

D. Reidel Publishing Company

Dordrecht / Boston / Lancaster

Published in cooperation with NATO Scientific Affairs Division 
Proceedings of the NATO Advanced Study Institute on

Chemistry of Ions in the Gas Phase

Vimeiro, Portugal

September 6-17, 1982

\section{Library of Congress Cataloging in Publication Data}

NATO advanced study institute on Chemistry of ions in the gas phase (1982: Vimeiro, Lisbon, Portugal)

Ionic processes in the gas phase.

(NATO advanced science institutes series. Series C, Mathematical and physical sciences : v. 118)

"Proceedings of the NATO advanced study institute on Chemistry of ions in the gas phase, Vimeiro, Portugal, sept. 6-17, 1982"-verso t. p.

"Published in cooperation with NATO scientific affairs division."

Includes index.

1. Ions-Congresses. 2. Gas dynamics-Congresses. I. Ferreira, M. A. Almoster. II. North Atlantic Treaty Organization. Scientific affairs division. III. Title. IV. Series.
QD561.N36
1982
$541^{\prime} .0424$
83-22980

ISBN-13:978-94-009-7250-6 e-ISBN-13:978-94-009-7248-3

DOI: $10.1007 / 978-94-009-7248-3$

Published by D. Reidel Publishing Company

P.O. Box 17,3300 AA Dordrecht, Holland

Sold and distributed in the U.S.A. and Canada

by Kluwer Academic Publishers,

190 Old Derby Street, Hingham, MA 02043, U.S.A.

In all other countries, sold and distributed

by Kluwer Academic Publishers Group,

P.O. Box 322, 3300 AH Dordrecht, Holland

D. Reidel Publishing Company is a member of the Kluwer Academic Publishers Group

All Rights Reserved

๑ 1984 by D. Reidel Publishing Company, Dordrecht, Holland.

Softcover reprint of the hardcover 1st edition 1984

No part of the material protected by this copyright notice may be reproduced or utilized in any form or by any means, electronic or mechanical, including photocopying, recording or by any information storage and retrieval system, without written permission from the copyright owner. 
CONTENTS

DEDICATION vii

$\begin{array}{lll}\text { PREFACE } & \text { ix }\end{array}$

POTENTIAL ENERGY SURFACES AND THEORY OF UNIMOLECULAR DISSOCIATION

J. C。 Lorquet and B. Leyh 1

SCANNING METHODS FOR DOUBLE-FOCUSSING MASS

SPECTROMETERS

K. R. Jennings

CHARGE EXCHANGE MASS SPECTROMETRY

A. G. Harrison

ISOTOPE EXCHANGE IN ION-MOLECULE REACTIONS

D. Smith and N. G. Adams

ENERGETICS AND DYNAMICS OF ION-MOLECULE REACTIONS AT THERMAL ENERGIES

R. Marx

RECENT STUDIES OF GAS-PHASE REACTIONS OF ANIONS WITH ORGANIC MOLECULES

S. Ingemann, J. C. Kleingeld and

N. M. M. Nibbering

GAS-PHASE STUDIES OF THE INFLUENCE OF SOLVATION ON ION REACTIVITY

D。K. Bohme

EXOTHERMIC BIMOLECULAR ION MOLECULE REACTIONS WITH NEGATIVE TEMPERATURE DEPENDENCE

T. F. Magnera and P. Kebarle 
SPECTROSCOPIC STRUCTURE AND RADIATIONLESS DECAY OF OPEN-SHELL ORGANIC CATIONS

J. P. Maier, D. Klapstein, S. Leutwyler,

L. Misev and F. Thommen

GAS-PHASE ION PHOTODISSOCIATION

R. C. Dunbar

DISSOCIATION DYNAMICS OF ENERGY SELECTED IONS

STUDIED BY ONE AND MULTIPHOTON IONIZATION

T. Baer

SIFT-DRIFT STUDIES OF ANIONS

C. H. DePuy

DETERMINATIONS OF GAS-PHASE ORGANIC ION STRUCTURES

G. S. Groenewold and M. L. Gross

CARBON SKELETAL REARRANGEMENTS VIA PYRAMIDAL CARBOCATIONS

H. Schwarz, H. Thies and W. Franke

LOW RATE FRAGMENTATION REACTIONS OF GASEOUS IONS

M. A. Almoster Ferreira

APPLICATIONS OF THE FRANCK-CONDON FACTORS TO

POLYATOMIC MOLECULES

R. Botter and J. Carlier

ION CLUSTERS:

SUMMARY OF THE PANEL DISCUSSION

A. W. Castleman, Jr.

ION THERMOCHEMISTRY :

SUMMARY OF THE PANEL DISCUSSION

S. G. Lias

INSTRUMENTATION :

SUMMARY OF THE PANEL DISCUSSION

M. B. Comis arow 


\section{DEDICATION}

To J. L. Franklin and Henry M. Rosenstock

This volume is jointly dedicated to the memories of two of the preeminent pioneers of research in ion chemistry, J. L. Franklin and Henry M. Rosenstock.

Shortly before the beginning of the proceedings which are the subject of this book, the participants received word of the death of Joe Franklin. Many of those present for the N.A.T.O. ASI in Portugal had heard Professor Franklin deliver the introductory lecture at a N.A.T.O. ASI on "Interactions between Ions and Molecules," held eight years earlier in Biarritz, France, and it seemed particularly appropriate that the group of his colleagues and friends assembled in Portugal honor him by dedicating this volume to his memory. Joe Franklin received his $\mathrm{Ph}$. D. in physical chemistry from the University of Texas in 1934, and went to work for the Humble Oil and Refining Company at Baytown, Texas, where he remained until joining the faculty of the Chemistry Department at Rice University in 1964. In the early 1950 's, he became active in the then-emerging field of mass spectrometry, and, in collaboration with Drs. Frank Field, Fred Lampe, and Burnaby Munson, carried out much of the significant pioneering work on ionization potential and appearance potential measurements and on ion-molecule reactions. In 1957, there appeared "Electron Impact Phenomena" by F. H. Field and J. L. Franklin, the first really comprehensive treatise on the subject of ion chemistry. In more recent years, he has continued to make so many important contributions to every area of the field that it would be difficult or impossible to name them all here. It is likely that most readers of this volume will have some personal familiarity with the work of Joe Franklin since his name is, and will continue to be, synonomous with ion chemistry.

One of the participants at the N.A.T.O. ASI on "The Chemistry of Ions in the fas Phase" in Portugal was Henry M. Rosenstock, who had helped to organize the ASI. In the early 1950's when Joe 
Franklin was beginning his work in mass spectrometry, Henry Rosenstock was a graduate student at the University of Utah, working on developing a theoretical picture of the dissociation of ions under collision-free conditions. The resulting QuasiEquilibrium Theory, or so-called OET, is still an important tool for ion chemists, referred to many times in the proceedings of the ASI. After receiving his $\mathrm{Ph}$. D. in 1952, Henry Rosenstock worked for several years at the Oak Ridge National Laboratory and in private industry before joining the National Bureau of Standards in 1960, where he directed a research team working in the areas of photoionization mass spectrometry, and, later, photoionphotoelectron coincidence measurements. From 1966 to 1968 he served as chairman of the American Society for Testing Materials Committee E-14 on Mass Spectrometry. He was succeeded as chairman by Joe Franklin, and together, they shared a large part of the responsibility for the establishment and early leadership of the American Society for Mass Spectrometry, now a major professional organization for scientists in the field of ion chemistry. In 1963, Henry Rosenstock initiated a program of compiling and evaluating data on ion thermochemistry, building initially on a small compilation which had appeared as an Appendix in Field and Franklin's "Electron Impact Phenomena." The initial publication resulting from this effort in 1969, "Ionization Potentials, Appearance Potentials, and Heats of Formation of Gaseous Positive Ions" by J. L. Franklin, J. G. Dillard, H. M. Rosenstock, J. T. Herron, K. Draxl, and F. H. Field, is still the most widely cited single publication in ion chemistry. Henry Rosenstock participated actively and enthusiastically in the proceedings in Portugal, sitting in the front row at every lecture, asking questions and making comments, and obviously enjoying himself very much. On the morning of Tuesday, September 14, 1982, he suffered a heart attack and died that afternoon shortly after being taken to a hospital in Lisbon. His death, no less than that of Joe Franklin, will be felt by the ion chemistry community of the world as a great loss.

\author{
M.A. Almoster Ferreira \\ P. Aus 1 oos \\ R. Botter \\ A. Ferrer Correia \\ $\mathrm{K}$. Jennings \\ S. Lias
}


PREFACE

The field of gas phase ion chemistry has undergone spectacular growth and development in the last decade. New experimental techniques have developed and theoretical advancements in quantum chemistry and chemical dynamics have begun to provide quantitative information, deeper insights and important guideposts for experiments. The growing interaction between theoreticians and experimentalists is yielding scientific information of both basic and applied significance.

The NATO Advanced Study Institute on Chemistry of Ions in the Gas Phase held at Vimeiro, Portuga1, from 6 to 17 September 1982 took place four years after the 1978 Advanced Study Institute on Kinetics of Ion-Molecule Reactions held at la Baule, France. New theoretical approaches and experimental techniques developed since then are included in this book. Fundamental aspects concerning the kinetics and dynamics of formation and decomposition of gaseous positive and negative ions, their structural characterisation, energetics and thermochemistry are also discussed. In addition, some recent innovative developments in the areas of photodissociation, multiphoton ionisation, photoelectron-photoion coincidence spectroscopy, selected ion flow tube technique, and other techniques will be found.

The success of the NATO Advanced Institute on Chemistry of Ions in the Gas Phase was mostly due to the high quality of the lectures, panel sessions, research review contributions and the ensuing important discussions which would informally continue after the scheduled sessions. All the participants were ultimately responsible for the attainment of the aims of the Institute. 
I would like to express my appreciation for the great assistance and support I always received from the members of the Organising Committee P. Ausloos, R. Botter, A. Ferrer-Correia, K. Jennings and S. Lias. I am very grateful for the efforts and enthusiastic help of my research group in the organisation of the meeting and for the efficient secretarial work of Mrs. Isabel Freire who also helped with the typing of parts of this book.

On behalft of all the participants I want to thank the Scientific Affairs Division of the North Atlantic Treaty Organisation whose grant made it possible to organise the meeting. Financial support from Instituto Nacional de Investigação Cientifica, Portugal, and student travel grants from the National Science Foundation, USA, are also gratefully acknowledged.

Finally I should like to mention the understanding and valuable guidance I always found in Dr. Mario di Lu11o and in Dr. Craig Sinclair of the Scientific Affairs Division of the North Atlantic Treaty Organisation.

Lisbon, May 1983

M.A. Almoster Ferreira 